\title{
SPONTANEOUS RUPTURE OF THE TENDON OF EXTENSOR POLLICIS LONGUS AS A COMPLICATION OF RHEUMATOID ARTHRITIS
}

\author{
BY \\ R. HARRIS \\ Rheumatism Unit, Royal Free Hospital, London
}

Numerous authors have recently stressed the frequent clinical evidence of tendon involvement in rheumatoid arthritis. Edström (1945) found evidence of " tendinitis ", or " peritendinitis ", in 48 per cent. of 391 cases of chronic rheumatic polyarthritis. The long flexors to the fingers were involved in 38 per cent. of his cases, and the extensors in 10 per cent. Kellgren and Ball (1950) analysed 100 of their own cases, and found tendon lesions present in 42, in 37 of which the long flexors of the fingers were affected. Other tendons described as clinically affected were the extensors of the fingers, the tendons around the ankle, and Achilles' tendon, but no mention was made of the extensor pollicis longus. Fifteen of their cases were explored, and the clinical findings confirmed at operation. They emphasized that in most cases of rheumatoid arthritis the tendon lesions were only one aspect of " a generalized process involving joints, muscles, and occasionally viscera ", but that in rare cases the tendon lesions may be the chief cause of disability. The disabilities described were snapping fingers (Helweg, 1924; Sperling, 1949, 1950; Kellgren and Ball, 1950), weakness of grip (Edström, 1945), and inability to clench the fist. No cases of rupture of tendon were quoted, nor was this described as a possible occurrence.

Kersley (1948), in a short paper, described two cases of spontaneous muscle rupture occurring in rheumatoid arthritic subjects. No similar cases have been described elsewhere. In his first case, the muscle ruptured was in the calf (? gastrocnemius); in the second, multiple lesions were described. In addition to the rupture of the quadriceps, which appeared to be at the musculo-tendinous junction, there were spontaneous ruptures of the extensor apparatus of the fourth digit of the right hand, and the flexor digitorum profundus of the third digit of the left hand. The patient's description of the spontaneous rupture of the extensor digitorum was "a slight pain, like an electric shock, running up the forearm ". The site of these lesions was considered to be in the forearm, probably at the musculotendinous junction.

Both these cases were males, one aged 56, the other 54 . In the first case, a typical rheumatoid arthritis had been present for one and a half years, in the second the quadriceps rupture occurred two years after the onset of the disease, the extensor rupture a further one and a half years later. 
Platt (1931), discussing tendon ruptures, described two groups:

(i) A common type, produced by the sudden powerful over-stretching of a muscle already in a state of contraction.

(ii) A less common form-spontaneous rupture-seen in certain tendons which occupy bony grooves.

He considered the tendons most likely to rupture to be the extensor pollicis longus and the long head of the biceps. The spontaneous rupture of the extensor pollicis longus occurred as an isolated lesion, e.g. " kettledrummers' palsy "' (Von Zander), generally preceded by a painful tenosynovitis caused by prolonged use of the drumstick - or associated with a fracture, usually of the Colles type. In this group, the tendon rupture takes place some weeks after the occurrence of the bony injury, and the " sequence is fracture, distortion of the tendon groove, adherence of the tendon, attrition, rupture ". Of the seven cases he described, one followed an occupational tenosynovitis, and six were associated with a fracture of the lower end of the radius.

Platt considered the diagnosis of rupture of the extensor pollicis longus tendon depended on the following signs:

(i) Inability to extend the dropped terminal phalanx of the thumb against resistance.

(ii) Absence of the subcutaneous bowstring normally formed by the tendon when the thumb is fully extended.

He also noted these two additional points:

(iii) It is sometimes possible to feel the distal part of the divided tendon.

(iv) The loss of function may be demonstrated by stimulating the muscle belly by a faradic current.

McMaster (1932, 1933) considered that in all cases of spontaneous rupture of the extensor pollicis longus there was a pre-existing tendon disease or injury. The commonest causes were a chronic tenosynovitis, which occurred in drummers, and as a late sequel of Colles fracture. For the latter, he considered the cause was either a partial severance at the time of injury, or a local tendon necrosis caused by injury to the blood supply of the tendon at the time of fracture. Pathological conditions predisposing to tendon rupture included tuberculous tenosynovitis, gonococcal tenosynovitis, syphilis, and tendon tumours. From a series of experiments on rabbit tendon, in which he determined the tensile strengths and points of rupture of normal, crushed, partly-severed, and resutured tendons, and tendons ligatured so as to obstruct their blood supply, he concluded:

Normal tendons do not rupture. Instead, the tendon insertion or muscle origin gives way, or the muscle belly ruptures, or the musculo-tendinous junction separates, or the bones fracture.

In addition he found that obstruction of the blood supply of the tendon gave rise to a spontaneous rupture at the site of obstruction in about four weeks, even when the tendon sheath had been replaced carefully.

\section{Cases Previously Reported}

(1) Von Stapelmohr (1940) surveyed the literature on spontaneous rupture of the extensor pollicis longus, and analysed 148 cases, the total he was able to find recorded, including his personal series. He quoted Pirker (1934) as considering that rheumatic infections 
were of significance in causing a mesotendinitis and paratendinitis predisposing to the rupture, but the detailed analysis of the 148 cases included only one in which a polyarthritis of the rheumatoid type was present. Two-thirds of the cases were in women, and the age varied between 16 and 74 . The right hand was slightly more commonly involved than the left $(68: 56)$. In some cases the rupture was preceded by a crepitant tenosynovitis. The case history of the one "rheumatic" subject was as follows:

A dental mechanic aged 25 had a polyarthritis which followed a carditis at age 8 . Both wrists were involved. Without any history of local trauma, he suddenly lost extension of the right thumb. $X$ ray showed decalcification of the hand and loss of cartilage of the thumb and wrist. At operation, rupture of the extensor pollicis longus was found située distale à la coûture du carpe. It was impossible to repair the tendon by direct suture, and the distal end was inserted into the extensor carpi radialis brevis. No microscopic examination was made.

(2) Wadstein (1946), in a paper on spontaneous rupture of the tendon of extensor pollicis longus, described the condition as being rare, both absolutely and in relation to other very common injuries of the wrist. He quoted von Stapelmohr as seeing three out of 1,250 injuries of the wrist $x$ rayed at Norrköping Hospital from 1927 to 1937, of which 1,000 were fractures of the radius; Moore as seeing three out of 500 fractures of the radius; and Oppolzer as seeing two out of 800 fractures of the radius. He himself described two cases seen personally; one, which he considered to be due to " rheumatism " is described as follows:

A male, aged 37, was "always perfectly healthy, and never had any pains in the joints". Two months before admission to hospital, he had pain and swelling of the left wrist, which gradually improved. Five weeks later he noticed suddenly that he was unable to extend the left thumb. Examination of the left wrist and forearm showed no signs of inflammation or muscle atrophy. The Wassermann reaction was negative, and the erythrocyte sedimentation rate was $18 \mathrm{~mm}$., falling to $9 \mathrm{~mm}$./ $\mathrm{hr}$. in a week. $X$ ray of the hand was negative; clinically there was a $45^{\circ}$ loss of extension of the thumb, and the tendon of the extensor pollicis longus did not appear in the snuff-box.

A nerve injury was suspected, and " neuritis" was diagnosed by a neurologist: however, the wrist was explored and at operation the tendon was found divided, the ends being widely separated. Both ends were thickened, oedematous, and degenerate, but the muscle showed no gross abnormality. A tendon transplant of the extensor indicis was performed, with excellent functional results. The pathologists "report was as follows:

A chronic tendinitis. In the middle of the tendon as well as on its outer part are nests of granuloma. There are no certain signs of anything extraordinary, but rheumatic granulation may be surmised.

Wadstein accepted this report, but commented:

It may seem surprising that a man quite healthy in other respects should get a rheumatic affection only in this part of the body !

(3) Only one case of bilateral rupture of the extensor pollicis longus is fully described in the literature (Andreasen, 1934):

After a motor-cycle accident, a man of 30 injured both wrists. One tendon ruptured 5 days later, and the second after a further 10 days.

Von Stapelmohr (1940) refers also to another case, but gives no details. Thus bilateral spontaneous rupture of the extensor pollicis longus tendon without any previous injury does not appear to have been described in medical literature.

\section{Present Series of Cases}

In view of the apparent rarity of spontaneous rupture of the extensor pollicis longus, its occurrence in a series of cases of rheumatoid arthritis seems worth reporting. The following five cases were observed between April, 1949, and April, 
1951. Case 3 was seen at the Royal National Hospital for Rheumatic Diseases, Bath, by permission of Dr. G. D. Kersley. Cases 4 and 5 were not personally seen by the author.

Case 1.-A civil servant, aged 43, had a typical generalized rheumatoid arthritis of five years' duration, involving hands, wrists, shoulders, feet, and knees. He was Stage III, Class II, by the classification of Steinbrocker and others (1949). The erythrocyte sedimentation rate was $20 \mathrm{~mm}$. and the Wassermann reaction negative. He was right-handed.

Whilst gardening he suddenly noticed the whole right thumb "went into a cramp ". Five minutes later he noticed that he had lost extension of the terminal phalanx of this thumb. Thirty minutes later he felt a tightness in the mid-forearm. Two weeks later while taking off a pullover, he felt a sudden cramp in the muscles of his left forearm, and immediately noticed that the left thumb had become flexed at the terminal phalanx, and that he had lost the power of active extension there. He was seen in the Out-patient Department of Leeds General Infirmary two weeks later. He had no disability other than a loss of power of extension of the terminal phalanx of both thumbs, which were held in about $30^{\circ}$ of flexion. Both wrists were thickened. All Platt's criteria were present on both sides. Typical rheumatoid deformities of the fingers were present. A palpable mass was present in the left forearm $2 \frac{1}{2}$ in. proximal to the radial styloid, which moved on attempting extension of the thumb. The tendon of extensor pollicis longus could not be demonstrated as a boundary to the snuff-box on attempting thumb extension against resistance. The findings were identical on the right side.

Radiographs of the wrist showed some osteo-porosis of the bones of the hands and wrists, with some cystic changes present in the right carpus. No hypertrophic bone was seen on the dorsum of the radii and there was no evidence of old fractures or deformities.

Faradic stimulation was applied to individual forearm muscles by a small electrode. The mass previously observed could be felt to move proximally when the muscle contracted, but no extension of the terminal phalanx of the thumb could be obtained.

Operation was refused by the patient as function was good. Six months later his rheumatoid arthritis had settled considerably, after a long course of gold injections. The condition of the thumbs was unchanged.

Case 2.-A textile worker, aged 45, doing a skilled manual job, had a history of rheumatic fever when aged 17. He developed a typical generalized acute polyarthritis of the rheumatoid type 18 months before the tendon rupture, involving the hands, wrists, feet, and knees. He was receiving in-patient treatment at the Royal Bath Hospital, Harrogate, and had had courses of both gold and copper, in addition to extensive physiotherapy. He was right-handed.

One day whilst unknotting the string round a small parcel, he felt a sudden pain on the dorsum of the left wrist, and up the forearm. He then noticed that " his thumb had dropped into the palm of his hand ", and then he was unable to extend it. A plaster splint was applied within three hours, with the thumb extended. Twelve hours later he felt a sudden pain "like an electric shock" in the thumb. On examination next day, he was seen to be a rather wasted man, with a severe general and active rheumatoid arthritis. His hands, wrists, and knees were severely involved, although there was no ankylosis of the joints, and no fixed deformity of the fingers. He was Stage III, Class III, by the Steinbrocker classification. His erythrocyte sedimentation rate was $46 \mathrm{~mm}$. and his Wassermann reaction negative. Active extension of the terminal phalanx of the left thumb was absent, and when unsupported this fell into $45^{\circ}$ of flexion. The tendon of extensor pollicis longus was not palpable at the wrist when an attempt was made to extend the thumb. The proximal end of the tendon could not be felt. Radiographs of the wrist showed no abnormality other than osteo-porosis. A diagnosis of spontaneous 
rupture of the extensor pollicis longus was made, and confirmed at operation 10 days later (Mr. H. Petty). The tendon of the extensor pollicis longus was found divided proximal to the level of the groove in the radius. The proximal end had retracted well up the forearm. Direct repair was not possible. Transplantation of the tendon of extensor carpi radialis brevis to the distal end of the tendon of the extensor pollicis longus was performed with excellent functional results. The proximal portion of the tendon, along with some of the muscle was removed for histological examination.*

Nature of Specimen.-Ruptured tendon of extensor pollicis longus.

Macroscopic Appearance. $-1 \frac{1}{4}$ in. of tendon, the distal $\frac{1}{4}$ in. is marked with surgical clamp and was cut away before blocking. The proximal $\frac{1}{2}$ in. is surrounded with blood clot and/or muscle fibres.

Histology.-Sections have been cut in the long axis of the proximal part of the ruptured tendon, and include a large area of muscular attachment. The site of the rupture is not included since the distal portion of the tendon was not removed and the tendon fibres at the distal end of the excised portion are crushed and torn by the surgical clamp. Pathological changes, however, are extensive in the part which is suitable for histological examination. The collagen fibres of the tendon itself appear normal by both ordinary and polarized light. The bundles show a wavy outline resulting from their slight retraction. Several small blood vessels are seen in the body of the tendon and these are in relation to elongated foci of lymphocytes with occasional polymorph and eosinophil leucocytes intermingled with proliferated endothelial cells and fibroblasts. This chronic inflammatory cellular reaction is much more marked at the edge of the tendon beneath the muscle attachment and between the fibres of voluntary muscle, where there are quite considerable foci of lymphocytes, many fair-sized, thin-walled, blood vessels, and some cellular fibrosis of the endomysium. The synovial covering on either side of tendon and muscle, shows fibroblastic proliferation, great vascularity, and diffuse lymphocytic infiltration with a scattering of eosinophils and polymorphs. Flakes of fibrin deposit are to be seen on one surface. In one or two areas there are small aggregations of histocytes near a vessel wall, between which collagen fibres, showing fibrinoid change, can be identified. Many of the muscle fibres at the extreme distal end of the muscle attachment show waxy degeneration, but with persistence of muscle-cell nuclei beneath the sarcolemma.

The lesion, which is of chronic inflammatory type and can be compared with the lesions of rheumatoid arthritis seen in other sites, may be summarized thus:

(1) rheumatoid tenosynovitis.

(2) rheumatoid myositis with chronic inflammation and lymphocytic infiltration in the endomysium and waxy degeneration of muscle bundles.

(3) vascularization and lymphorrhages in the substance of the tendon.

The whole disturbance can be related to rheumatoid arthritis, and it is probable that this rheumatoid tendinitis has occasioned rupture of the tendon.

Case 3.-A manual worker, aged 58, a heavily-built man, had a history of rheumatic fever in 1930, when he had been treated in hospital for several months, and had made a complete recovery. Since then, he has always worked as a weighing-machine fitter-a skilled, heavy, manual job. He is right-handed. In 1945 he developed pain and swelling of his hands, feet, elbows, and shoulders. A diagnosis of rheumatoid polyarthritis was made at a specialized rheumatism unit, and he received several courses of gold injections in 1947, 1948, and 1949.

In 1949, that is, 4 years after the onset of his rheumatoid arthritis, he was lifting a weight of about $56 \mathrm{lb}$. with another man, when he felt a sudden tingling in the left thumb and forearm. His grip became weak and he stopped work. Next day, he noticed that his "left thumb had dropped". At that time his left hand was clinically little affected by the rheumatoid process, and he himself considered it to be his " best hand ".

He was seen at a rheumatism clinic six months later, complaining of his generalized arthritis. Both wrists were thickened and swollen. The erythrocyte sedimentation rate was $48 \mathrm{~mm}$. (Wintrobe), and the condition was active. The spontaneous rupture of the extensor pollicis longus was noted, and repair suggested. This the patient refused, as he

* I am indebted to Dr. D. H. Collins for this report. 
considered the disability to be slight, and it did not interfere with his work. $X$ ray showed some osteo-porosis of the carpal bones.

When seen two years later, in 1951, at the National Hospital for Rheumatic Diseases, Bath, he had an active polyarthritis of the rheumatoid type, involving hands, wrists, elbows, shoulders, and feet. He was Stage III, Class III, by the Steinbrocker classification. He had soft, crepitant swellings about both wrists, and nodules at both elbows. His hands were soft and loose with little deformity of the proximal interphalangeal joints, but thickening of the metacarpophalangeal joints of both hands. There was obvious wasting of all interossei, and a little thenar loss of tone. There was loss of active extension of the terminal phalanx of the left thumb, and the tendon of the extensor pollicis longus was not palpable at the wrist. The erythrocyte sedimentation rate was $39 \mathrm{~mm}$. (Wintrobe), and radiographs of the wrist showed no change from those taken 2 years earlier. He had no complaints of the function of his left hand, other than a general weakness of grip.

Case 4.-A bus-driver, aged 56, had a generalized rheumatoid arthritis of 10 years' duration. He had deep $x$ ray to his wrists and knees in 1949, and in August, 1950, a course of insulin hypoglycaemia, with slight improvement. In February, 1951, whilst washing, he developed pain and swelling of the left wrist, there being no injury of any kind. When seen a week later at the National Hospital for Rheumatic Diseases, Bath, he was found to have a spontaneous rupture of the left extensor pollicis longus. Clinically the disease was moderately active, with involvement of the knees, ankles, and wrists. The erythrocyte sedimentation rate was $66 \mathrm{~mm}$. in the first hour (Westergren). He was right-handed.

Operation was suggested, but the patient was able to carry on with his work, and therefore refused it.

Case 5.-A dentist's wife, aged 51, who had been suffering from a generalized rheumatoid arthritis for 4 years, suddenly felt something "go snap" in the left wrist. Her rheumatoid condition was active at the time, the erythrocyte sedimentation rate being $50 \mathrm{~mm}$. (Wintrobe). She was seen by Dr. G. D. Kersley, and a spontaneous rupture of the extensor pollicis longus was diagnosed. A fortnight later the wrist and forearm were explored; the tendon was found ruptured, and was repaired by transplantation of the extensor indicus proprius into the distal part of the ruptured tendon. A good functional result was obtained.

The findings are summarized in the following Table, to which the cases of von Stapelmohr and Wadstein have been appended.

TABLE

CASES OF RUPTURE OF EXTENSOR POLLICIS LONGUS

\begin{tabular}{|c|c|c|c|c|c|c|c|c|}
\hline $\begin{array}{l}\text { Case } \\
\text { No. }\end{array}$ & Sex & Age & $\begin{array}{c}\text { Duration } \\
\text { (yrs.) }\end{array}$ & $\begin{array}{l}\text { E.S.R. } \\
\text { (mm.) }\end{array}$ & Hand & $\begin{array}{c}\text { Operative } \\
\text { Repair }\end{array}$ & Function & $\begin{array}{c}\text { Rheumatic } \\
\text { Fever }\end{array}$ \\
\hline 1 & $\mathbf{M}$ & 43 & 5 & 20 & Both & - & v. good & - \\
\hline 2 & $\mathbf{M}$ & 45 & $1 \frac{1}{2}$ & 46 & $\mathbf{L}$ & + & v. good & + \\
\hline 3 & $\mathbf{M}$ & 56 & 4 & 48 & $\mathbf{L}$ & - & good & + \\
\hline 4 & $\mathbf{M}$ & 56 & 10 & 66 & $\mathbf{L}$ & - & v. good & - \\
\hline 5 & $\mathbf{F}$ & 51 & 4 & 50 & $\mathbf{L}$ & + & good & - \\
\hline $\begin{array}{l}\text { Stapel- } \\
\text { mohr }\end{array}$ & $\mathbf{M}$ & 25 & 17 & - & $\mathbf{R}$ & + & good & + \\
\hline Wadstein & $\mathbf{M}$ & 32 & $2 / 12$ & 18 & $\mathbf{L}$ & + & excellent & - \\
\hline
\end{tabular}




\section{Discussion}

In view of the histological findings in Case 2, there seems little doubt that spontaneous rupture of the tendon of extensor pollicis longus can occur as a result of the rheumatic disease process. This is strongly supported by the bilateral lesion in Case 1. All five cases reported are closely similar. In each a rheumatoid arthritis of moderate severity was present in a relatively young subject, and the rupture occurred during normal everyday activity without obvious predisposing trauma. Several features seem worth discussing in detail.

Sex.-The sex incidence is possibly significant. Four of the five cases occurred in male subjects, whereas two-thirds of the 148 patients reported by von Stapelmohr were women. In addition, rheumatoid arthritis is more frequent in women than men. Kersley (1950) gives the figures of five women to one man. In this series, the ratio of women to men was approximately $2 \cdot 4: 1$ (306:127). If the two cases of von Stapelmohr and Wadstein are added to the series, the sex incidence becomes even more decisive, as both their cases were males.

Occupation.-The type of occupation may be of some importance. Case 1 was a civil servant, doing clerical work, but his first rupture developed whilst digging. Case 2 was a weaver, doing work involving considerable manual skill, and had been a hospital in-patient for 2 months before his rupture. Case 3 was a machine fitter, doing work that involved both skilled movements and heavy manual labour, and his rupture took place during heavy lifting. Case 4 was a bus-driver, whose hands were thus in constant use. Case 5 did light household duties. The heavier type of work done by men may be the cause of the preponderance of the lesion in men. All the subjects were right-handed, yet the rupture was left-sided in four cases, and bilateral in one. It is difficult to suggest any explanation for this.

Age.-The age range of the five cases was very small, lying between 43 and 56 . The cases of Wadstein and von Stapelmohr were rather younger.

Activity of Disease.-All cases were in an active stage of the disease at the time of the rupture, both clinically, and as shown by the erythrocyte sedimentation rate, which varied between 20 and $66 \mathrm{~mm}$. in the first hour.

Duration of Disease.-This varied between $1 \frac{1}{2}$ and 10 years before the rupture.

Rheumatic Fever.-Two of the five cases ( 2 and 3$)$ had histories of rheumatic fever during young adult life. Von Stapelmohr's case also had a " polyarthritis following a carditis " when a child-probably a rheumatic fever.

The exact frequency of rheumatoid arthritis following rheumatic fever is uncertain. The most recent work on the correlation of the two conditions is that of Bywaters (1950), who analysed the literature and a personal series of cases of rheumatic heart disease in rheumatoid arthritis. Of a total number of 241 cases of rheumatoid arthritis described in several series since 1943, autopsy evidence of rheumatic heart disease was found in 34 per cent. Bywaters' own figures of 18 per cent. were reduced to 7 per cent. if the Jaccoud type of chronic fibrous rheumatism following rheumatic fever was excluded. Of a total number of 420 cases of rheumatoid arthritis described in several series since 1943, clinical evidence of 
rheumatic heart disease was found in 5 per cent. Though these figures gave no real indication of the number of cases of rheumatoid arthritis with a previous history of rheumatic fever, they suggest that the clinical association of the two (as opposed to autopsy evidence) is uncommon.

The evidence of a previous history of rheumatic fever in this series is much higher $(2: 5)$ than might be expected, and it may be significant, although the numbers are too small to be of statistical value. In the cases examined in this series, no confirmatory evidence of the history of rheumatic fever was obtained. There was no clinical evidence at the time. No electro-cardiographs were made, but these may well be worth doing on any further cases seen. Although tendons are involved in rheumatic fever (Bywaters, 1950, considers tendon crepitus to be a feature), tendon ruptures have not been described in this disease.

Treatment and Function.-Function was good in all cases, with or without operative repair, and this is probably a reason for the relative infrequence of the diagnosis of the lesion. Deformities of the hand and muscle weakness are accepted by the patient as a feature of the disease. Cases 1, 3 and 4 were diagnosed during routine examination, without any particular complaint by the patient, because the cases were seen by clinicians interested in muscle and tendon lesions in rheumatoid arthritis. (The author had previously seen one of the cases of muscle rupture described by Kersley in 1948.)

Frequency.-The lesion is uncommon. As previously pointed out, the patient may not complain of the loss of thumb extension, and function is usually little impaired. Case 1 did not even complain of bilateral loss; it was found during an investigation of wasting of the muscles of the hands in rheumatoid arthritis, during which 125 cases attending the Rheumatism Out-Patient Clinic at Leeds General Infirmary in 1949 were studied. In no other subjects were tendon ruptures found. During the same period, eighty cases of rheumatoid arthritis were similarly investigated at the Royal Bath Hospital, Harrogate, and tendon rupture was found only in Case 2. This gives a total of two out of 205 cases. The next year, 228 cases of rheumatoid arthritis were examined in detail at the Rheumatism Clinic of the Royal Free Hospital, London, and no tendon ruptures were found. This brings the figure for the number of ruptures found on detailed, but routine, clinical examination to two out of 433 cases (approx. $0 \cdot 5$ per cent.).

\section{Summary}

(1) The literature on spontaneous rupture of the tendon of the extensor pollicis longus is reviewed, and the occurrence of tendon lesions and spontaneous muscle ruptures in rheumatoid arthritis is noted. Only two cases could be found in the literature in which rheumatoid polyarthritis was considered to be the causative factor.

(2) A series of five cases (one bilateral) occurring as a complication of rheumatoid arthritis are described, and the relative frequency, sex incidence, and other possible aetiological factors of the tendon rupture are discussed. 
I am indebted to Dr. G. D. Kersley of the Rheumatism Research Unit, Bath, for permission to use his Cases 3, 4, and 5, to Dr. L. Mandel for kindly providing the histories of Cases 4 and 5, to Dr. D. H. Collins for his pathological report on Case 2, to Mr. $\mathrm{H}$. Petty for operating on Case 2, to Professor S. J. Hartfall for permission to use his cases at Harrogate and Leeds, and to Dr. E. Fletcher for permission to use his cases at the Royal Free Hospital, London. I also wish to thank Dr. E. Fletcher and Dr. G. D. Kersley for their advice and encouragement.

\section{REFERENCES}

Andreasen, A. T. (1934). Brit. med. J., 2, 515.

Bywaters, E. G. L. (1950). Brit. Heart J., 12, 101.

Edström, G. (1945). Nord. Med., 25, 379.

Helweg, J. (1924). Klin. Wschr., 3, 2383.

Kellgren, J., and Ball, J. (1950). Annals of the Rheumatic Diseases, 9, 48.

Kersley, G. D. (1948). Brit. med. J., 2, 942.

-_ (1950). Clin. J., 79, 85.

McMaster, P. E. (1932). J. Bone Jt Surg., 14, 93. (1933). Ibid., 15, 705.

Pirker, H. (1934). Ergebn. Chir. Orthop., 27, 587.

Platt, H. (1931). Brit. med. J., 1, 611.

Sperling, I. L. (1950). J. med. Soc. N.J., 46, 430.

(1950). Annals of the Rheumatic Diseases, 9, 43.

von Stapelmohr, S. (1940). J. int. Chir., 5, 163.

Steinbrocker, O., Traeger, C. H., and Batterman, R. C. (1949). J. Amer. med. Ass., 140, 659.

Wadstein, T. (1946). Acta orthop. scand., 16, 194.

\section{Rupture Spontanée du Tendon du Long Extenseur du Pouce comme Complication de l'Arthrite Rhumatismale}

\section{RÉSUMÉ}

(1) On passe en revue la littérature sur la rupture spontanée du tendon du long extenseur du pouce et on enregistre l'apparition de lésions tendineuses et de ruptures spontanées des muscles au cours de l'arthrite rhumatismale. On n'a trouvé dans la littérature que deux cas où la polyarthrite rhumatismale a été considérée comme facteur causatif.

(2) On décrit cinq cas (dont un bilatéral) de complication de ce genre dans l'arthrite rhumatismale et on discute la fréquence relative, l'incidence selon le sexe, et d'autres facteurs étiologiques possibles de la rupture tendineuse.

\section{Ruptura Espontánea del Tendón del Extensor Largo del Pulgar como Complicación de la Artritis Reumatoide}

\section{Sumario}

(1) Se pasa en revista la literatura relativa a la ruptura espontánea del tendón del extensor largo del pulgar y se nota que lesiones tendinosas y rupturas espontáneas de los músculos suelen producirse en casos de artritis reumatoide. En la literatura se encontró solamente dos casos en los cuales la poliartritis reumatoide fué considerada el factor causante.

(2) Se describe cinco casos (uno bilateral) de complicación de este tipo de la artritis reumatoide y se discute la frecuencia relativa, la incidencia según el sexo, y otros factores etiológicos posibles en la ruptura tendinosa. 